\title{
Bullying escolar: a (in)visibilidade do fenômeno e dos protagonistas crianças
}

\author{
Acoso escolar: la (in)visibilidad del fenómeno y de los protagonistas niños \\ School bullying: the (in)visibility of phenomenon and children protagonists
}

Rosana Coronetti Farenzena*

\section{Resumo}

Este artigo debruça-se sobre o bullying escolar, fenômeno complexo e ativo nas escolas. Com caráter inovador, também por estruturar-se sobre pesquisa qualitativa, traz resultados de um estudo desenvolvido com três turmas - pré-escola, $1^{\circ}$ e $3^{\circ}$ ano - de uma escola de educação básica portuguesa. A metodologia envolveu observações diárias nos tempos livres e formais, grupos focais com crianças e entrevistas individuais com professores e funcionárias. Constatamos que práticas de bullying, por diversas formas, são comuns nas três turmas e poucas vezes são percebidas pelos adultos. Crianças de ambos os gêneros exercem papéis de agressoras e de vítimas. No contexto, essas últimas ocupam um lugar social de incapacidade e de não pertencimento. Agressores habituais evidenciam impossibilidade para uma participação lúdica em jogos e brincadeiras. Participar em jogos e brincadeiras é uma condição determinante à pertença e evita possível vitimização. É comum que uma dupla ou um trio de alto desempenho escolar incite os demais pares para práticas de bullying. Pertencer à etnia cigana é um fator automático de discriminação. As crianças são capazes de uma leitura profunda e propositiva do contexto institucional. Há que ser questionado um modelo de escolarização, alheio às crianças e ao seu direito de participação.

Palavras-chave: Infância. Bullying escolar. Participação infantil.

\section{Resumen}

Este artículo es un estudio hecho sobre el acoso escolar, fenómeno complejo y activo en las escuelas. Con carácter innovador, también por estructurarse sobre pesquisa cualitativa, trae resultados de un estudio desarrollado con tres grupos - el kínder, $1^{\circ}$ y $3^{\circ}$ año de la primaria - en una escuela de educación básica portuguesa. La metodología envolvió observaciones diarias en los tiempos libres y formales, grupos direccionados a niños y entrevistas individuales con profesores y funcionarios. Constatamos que prácticas de acoso, por diversas maneras, son comunes en los tres grupos y pocas veces son percibidas por los adultos. Niños de ambos géneros ejercen papeles de agresores y de víctimas. En el contexto estos últimos ocupan un lugar social de discapacidad y de no pertenecer. Agresores habituales evidencian imposibilidad para una participación lúdica en juegos y niñerías. Participar en juegos y niñerías es una condición determinante a la integración y evita una posible victimización. Es común que en una pareja o en un trío de alto desempeño escolar estimule a las demás parejas para las prácticas de acoso. Pertenecer a la etnia gitana es un factor automático de discriminación. Los niños son capaces de una lectura profunda y positiva del contexto institucional. Hay que se cuestionar un modelo de escolarización, ajeno a los niños concretos y a su derecho de participación.

Palabras clave: Infancia. Acoso escolar. Participación infantil.

\author{
Recebido em 14/01/2020 - Aprovado em 27/02/2020 \\ http://dx.doi.org/10.5335/rep.v27i2.11426
}

Doutora em Estudos da Criança pela Universidade do Minho, Portugal. Professora na Universidade de Passo Fundo, colaboradora do Centro de Investigação em Estudos da Criança, da Universidade do Minho, membro da Rede Pikler Brasil. Orcid: https://orcid.org/0000-0001-7362-5093.E-mail: rosanafarenzena@gmail.com 


\section{Abstract}

This article focuses on school bullying, a complex and active phenomenon in schools. With innovative character, also because it is structured on qualitative research. It brings results from a study developed with three classes - preschool, 1st and 3rd year - of a Portuguese primary school. The methodology involved daily observations in leisure and formal time, focus groups with children and individual interviews with teachers and staff. It was noticed that bullying practices, in many ways, are common in all three classes and they are rarely noticed by adults. Children of both genders play the roles of aggressors and victims. In the context, the victims occupy a social place of disability and non-belonging. Habitual aggressors show impossibility for a playful participation in games and children's play. Participating in games and children's plays is a determining condition of belonging and avoids possible victimization. It is common for a pair or a trio with great academical performance incite the other peers for bullying practices. Belonging to a gipsy ethnical background is an automatic factor of discrimination. Children are capable of a deep and purposeful reading of the institutional context. A model of schooling, inattentive to uninvolved to concrete children and their right to participate, must be questioned.

Keywords: Childhood. School bullying. Child participation.

\section{Uma retomada dos estudos sobre o bullying}

Com a introdução de metodologias qualitativas, associadas às quantitativas, produziu-se um sentido de valorização da participação infantil nos estudos sobre o bullying. Esse alargamento metodológico associa-se à concepção de criança como um sujeito de direitos, apta a falar sobre as suas vivências e a influenciar o contexto de inserção social.

Dentre os participantes do bullying, há que dedicarmos atenção ao agressor e à vítima. Diversos estudos confirmam a seriedade das consequências para uns e outros (BOULTON; SMITH, 1994; CRAIG, 1998; KECHENDERFER-LADD; WARDROP, 2001; MEYER, 2011; OLWEUS, 1993, 1989; SMITH, 2013), de forma que as questões da agressão e da vitimização não podem ser justificadas enquanto práticas naturais da infância ou "treino para a vida" (PEREIRA, 2008).

A condição de observador do bullying tem recebido especial atenção, desde que estudos voltados à intervenção e à prevenção identificaram um potencial de ação positiva por parte das crianças que presenciam essas ações. Grande parte das agressões entre pares são testemunhadas. Esses observadores podem influenciar o curso dessas agressões: podem dar apoio e reforço positivo ao agressor ou à vítima; nada fazer; intervir para tentar cessar a agressão ou mesmo afastar-se da cena agressiva (SALMIVALLI; NIEMINEN, 2002).

Conforme Martins (2007), o maior grupo de observadores presencia atos de bullying sem interferir ou chamar adultos para que o façam, mesmo que não apoie diretamente $o$ agressor. 
Os comportamentos de bullying, distintos das brincadeiras agressivas, ou das lutas de brincadeira, em que não existe a intenção de magoar ou de causar danos (MARQUES, 2010), estão categorizados num conjunto de comportamentos em que é possível identificar estratégias de intimidação, que resultam em práticas violentas, intencionais, com caráter regular e frequente, exercidas individualmente ou em grupo. Referem-se à "vontade consistente e desejo de magoar ou amedrontar alguém quer fisicamente, verbal ou psicologicamente" (SMITH; SHARP, 1994, p. 2). São considerados atos de bullying: bater/agredir fisicamente; empurrar, tirar dinheiro/extorquir; danificar objetos; gozar; chantagear ou ameaçar, intimidar/meter medo; espalhar rumores/disseminar boatos; mentir sobre; falar mal, insultar; chamar nomes; fazer comentários ou gestos ordinários e/ou piadas sexuais; abusar ou assediar sexualmente; excluir, discriminar etc. (MATOS et al, 2009; SMITH \& SHARP, 1994). Das especificidades que distinguem o bullying das demais violências na escola destacamos: as agressões não resultam de provocações, têm caráter regular e ocorrem numa escala de assimetria de poder de um(ns) sobre o(s) outro(s). Geralmente, o agressor é mais forte e a vítima não está em condição de se defender ou de procurar ajuda (PEREIRA, 2008; FANTE, 2005).

Os comportamentos de bullying podem ser manifestados por meio direto e/ou indireto. Esses últimos não são de fácil identificação e, frequentemente, relacionam-se a quadros de vitimização com efeitos profundos e duradouros (PEREIRA, 2008).

Em relação aos subgrupos etários, diversos estudos, entre os quais os de Costa Pereira, Simões e Farenzena (2011) e DeHaan (2009) e Martins (1997), indicam uma diferenciação no uso dos recursos aos comportamentos agressivos. À medida que aumentam a idade e os anos de escolaridade, parece diminuir a frequência do bullying (DEHANN, 1997; OLWEUS, 1993). As formas verbal e física aparecem como as mais frequentes entre crianças e a exclusão como a forma mais frequente entre adolescentes, seguindo-se a verbal e, na sequência, a agressão física.

Esses resultados, reveladores de uma lógica socializadora, sugerem que a criança interpreta os significados sociais, as implicações de cada uma das formas de agressão e de vitimização, e opta por práticas agressivas de menor exposição social, ou seja, por aquelas associadas a menor visibilidade do ato, como a exclusão (MARTINS, 2009; PEREIRA, 2008; SKRZYPIEC; SLEE; MURRAY-HARVEY; PEREIRA, 2011).

Para Guerra, Williams e Sadek (2011) o ambiente social em que o aluno cresce influencia no seu envolvimento com a violência escolar. Também Ferrer; Ruiz; David; Amador; Orford (2011) e Estévez; Murgui; Musitu e Moreno (2008) apontam 
para a relevância do clima familiar e suas implicações com a violência escolar, tanto para vítimas quanto para agressores.

Diversos autores têm se dedicado a compreender as relações entre família e bullying. Olweus (1994) associa o pertencimento das vítimas a famílias com processos educacionais restritivos, ou mesmo excessivamente protetivos. Spriggs Iannotti, Ronald; Nansel; Haynie (2007) enfatizam que escasso apoio e controle por parte dos pais, e também o maltrato físico geram atitudes violentas nos filhos, que tendem a perdurar durante o tempo. Garcia e Madriaza (2006) ao analisaram determinantes da violência escolar situam a família como inibidora ou facilitadora da violência.

Estudos portugueses referem uma naturalização de práticas de bullying, quando não significadas como atos violentos e com esse teor problematizadas. Tratá-las como brincadeiras seria uma dessas evidências (COSTA; FARENZENA; SIMÕES; PEREIRA, 2013a, 2013b).

Segundo a definição de Boulton e Smith (1994), a vítima é alguém com quem frequentemente implicam ou, que lhe batem ou lhe atormentam ou, que lhe fazem outras coisas desagradáveis sem razão. Ser vítima tem ação desagregadora sobre a subjetividade do sujeito, repercute nas questões de autoimagem e de autoconceito, também compromete o sentimento de confiança básica em relação ao outro e interfere no seu desenvolvimento global (SANMARTIN, 2006).

Sobre as crianças vítimas de bullying, Carvalhosa, Lima e Matos (2001), em ampla revisão da literatura, apontaram um conjunto de características, dentre as quais: as vítimas típicas/passivas são mais deprimidas que outras crianças; têm mais sintomas físicos, como dores de cabeça e dores abdominais; sintomas psicossomáticos, nomeadamente falta de apetite, enurese, insônia e irritabilidade; menos amigos e maior dificuldade em fazê-los porque sofrem rejeição dos pares; não se sentem bem na escola etc.

Algumas das características das crianças vitimizadas que mais se repetem nos estudos são: insegurança, ansiedade, dificuldade em ser assertiva, medo excessivo e contínuo e dificuldade em dar respostas à agressão. Vivenciam a incerteza de não saberem se vão ficar sós ou se vão ter com quem brincar nos momentos de recreio escolar. $\mathrm{O}$ isolamento nos espaços do recreio ou na sala de a aula influência na sua condição de vulnerabilidade e facilita as agressões que lhe são dirigidas.

Quanto à criança agressora, frequentemente implica com outras e lhes faz coisas desagradáveis, para o que não precisa de atitudes provocativas por parte das vítimas, consideradas alvos fáceis (OLWEUS, 1991, 1994). Os resultados de algumas pesquisas associam crianças agressoras, que também podem ser vítimas agressivas, 
a características como: dificuldades no controle dos impulsos; expectativas de que a agressão resulta no controle da vítima; a certeza de que não sofrerão retaliações e a ausência de medo ou de remorso pela sua conduta, que percebem como justificada no contexto (OLWEUS, 1993; SMITH; SHARP, 1994; NEGREIROS, 2003). Tendem a ser mais populares que as vítimas, denotam elevada autoconfiança e, frequentemente, associam-se aos pares com perfil semelhante, que os apoiam nas práticas agressivas. Ao contrário das vítimas, não são isoladas socialmente.

Os recreios, territórios de maior liberdade, nem sempre planejados nos espaços, equipamentos e materiais que oferecem aos alunos (MARQUES; NETO; ÂNGULO; PEREIRA 2002), são momentos com alta incidência de atos de bullying, nos quais a ação do agressor é seletiva e avaliada. Nesse sentido, é preciso escolher o momento em que sua ação produzirá maior efeito sobre a vítima, surpreendendo-a, também observar para que a iniciativa não seja perceptível ao olhar adulto (SOUZA; PEREIRA; LOURENÇO, 2011).

Seja pelas violências dos atos de bullying, que mobilizam mal estar e sofrimento infantil, com implicações na aprendizagem e desempenho escolar, ou pelas perspectivas futuras à vida de agressores, vítimas e observadores, a escola não pode se omitir à responsabilidade de acompanhar, documentar e analisar criteriosamente a qualidade das interações entre crianças e crianças; adultos e crianças; adultos e adultos, no que se incluem as relações escola família (ROOS; SARMIVALLI; HODGES, 2011; CARVALHOSA, 2001). Nessas interações afirma-se uma determinada socialização, que deve estar em sintonia com os objetivos institucionais.

A evidência científica aponta para a redução do bullying por meio de políticas de escola, com a participação ativa de adultos e de crianças, na construção de um modelo de coexistência pacífica (OLWEUS, 1993, 2004; SALMIVALLI, 2010).

Quanto aos programas de intervenção, para prevenir ou reduzir o bullying, a grande maioria dos estudos mostra os bons resultados de um modelo ecológico, voltado ao desenvolvimento de recursos socioemocionais protetivos - pela consciência dos efeitos do bullying e pela empatia -, e a uma identidade coletiva/de grupo orientada pela decisão de garantir uma convivialidade assente no respeito e na cooperação. Essa perspectiva de intervenção mobiliza a comunidade escolar, nos seus diferentes segmentos, para que em corresponsabilidade, problematize, proponha, planeje e busque alternativas que concretizem as metas definidas nesse processo (BRONFENBRENNER, 1996; ESPELAGE, 2014; FERNANDES; SEIXAS, 2012; FANTE, 2005; LEE, 2011; OLWEUS, 1991; 2004; SALMIVALLI, 2010; SMITH; SHARP, 1994). 
Ações pontuais e direcionadas à abordagem individual não apresentam bons resultados. Esses são obtidos, de acordo com os estudos citados, em programas com um desenho de intervenção longitudinal, iniciados ainda na educação pré-escolar e consoantes a uma escola inclusiva assim garantida por confrontar - no sentido de desejar, buscar, construir, avaliar e interrogar - o conhecimento produzido nas próprias práticas, sem perder de vista a articulação com os princípios e fundamentos das Ciências Sociais e Humanas. Ao fazê-lo estabelece uma linha educativa fundada em valores éticos e humanos, em capacidades científicas e dialógicas, ou seja, na participação cidadã das crianças dos diferentes grupos etários.

\section{Metodologia}

O enquadramento do estudo que originou este artigo foi orientado pelo objetivo de conhecer e compreender, numa perspectiva crítica e propositiva, o fenómeno do bullying na educação infantil e no $1^{\circ}$ Ciclo da educação básica - $1^{\circ} \mathrm{CEB}$.

O contexto de investigação foi uma escola básica encravada em área urbana e pressionada à ampliação pela crescente lista de espera por vagas. Foram selecionadas, a partir da concordância dos diversos segmentos da comunidade escolar, uma turma de pré-escolar, uma de $1^{\circ}$ ano e uma de $3^{\circ}$ ano do $1^{\circ}$ CEB. Entrevistas individuais foram aplicadas a professores e funcionários.

Além de observações diárias no ambiente escolar, foram organizados dois grupos focais por turma, constituídos entre 03 e 06 participantes cada um. As idades das crianças variaram dos 05 aos 09 anos.

A referência a cada participante do grupo focal é indicada pela letra "P" = Participante, e pelo número que lhe foi atribuído, de 1 a 6 . A simbologia $\delta$ e $\odot$ corresponde ao gênero, e na sequência há o numeral indicativo da idade e ao grupo a que pertence - G1 ou G2. Para exemplificar: P3 5 G2 lê-se participante 3, do gênero feminino, idade de 5 anos e pertencente ao grupo 2 .

Em torno de 260 crianças estão matriculadas na escola, dessas aproximadamente 30 pertencem à etnia cigana e habitam um bairro social da mesma freguesia.

\section{Resultados}

Há, nas três turmas, clara manifestação de atos de bullying entre os pares, concretizados em diversas formas de agressões e em diferentes tempos e espaços da escola por crianças de ambos os gêneros. Ainda que frequentes no cotidiano escolar, 
muitas dessas práticas não são percebidas por professores e funcionários ou, se identificadas, nem sempre são destinatárias da atenção necessária.

Crianças da etnia cigana são apontadas, num primeiro momento, por crianças e adultos, como as grandes responsáveis pelos episódios de violência física, furtos, atos de bullying e pelo clima de insegurança nos recreios na escola. Todavia, tem outro desenho a realidade que desponta nas práticas e nas narrativas das crianças no decorrer do estudo, isto na medida em que o lugar da pesquisadora é significado como não sendo o dos adultos que atuam na escola, e em que no espaço dialógico dos grupos focais cresce, para os participantes crianças, o sentido de legitimidade da própria voz.

Evidencias de pormenores da problemática do bullying no contexto não são os únicos resultados de pesquisa. Dinâmicas de socialização são reveladas destacando-se a inequívoca implicação multigeracional nessa forma específica de violência, bem como na cultura escolar que se apresenta.

O conceito de bullying das crianças remete, inicialmente, apenas para a ação dos colegas de etnia cigana, generalizada como violenta e associada à prática de agressão física. "[...] quando as empregadas não estão por perto, os ciganos fazem bullying." $\mathrm{P} 4{ }^{\top} 8 \mathrm{G} 1$. "Os ciganos estragam esta escola." $\mathrm{P} 2 ð 9 \mathrm{G} 1$. "Há muito bullying dos ciganos com os outros alunos.” $\mathrm{P} 1{ }^{\lambda} 8 \mathrm{G} 1$. Condutas dos pares dessa etnia são ressaltadas como portadoras de violência no contexto: "[...] no recreio, no campo de futebol quando estamos a jogar futebol, os ciganos que estão a jogar fazem muitas faltas, mas faltas que aleijam mesmo. Uma vez o "P3 3 G 1 " levou uma falta que ficou muito penalizado, ficou muito a doer-lhe a perna." P1 ${ }^{\dagger}$ 9G2. "Como a P2 disse, o "J" é um cigano que também bate muito... P3 3 9G2. "Eles chegam a nossa beira, eles quando se enervam, soltam tudo o que têm lá dentro e aleijam bastante, já muita gente fica com marcas porque eles são muito violentos." "P2 $\bigcirc$ 9G2"; “[...] os ciganos não podem (brincar) porque são muito brutos" P5 9 9G1. A pertença ao grupo étnico cigano é associada a uma condição social anômala: É um cigano e muitas vezes não lava os dentes, eu nunca brinquei com ele.” P2 $ð 7 \mathrm{G} 2$; “...Só tem dois ciganos, mas o $\mathrm{C} \precsim 5$ é o que falta tantas, tantas vezes que não sabe nada." P3 9 6G2.

Racionalizações, voltadas à comunicação de pontos de vista afinados com expectativas sociais estão presentes nas lógicas das crianças das diferentes turmas: "Eu brinco com a $\mathrm{D}$ e é cigana. [...] ela é morena e é cigana também e eu brinco com ela. "P3ㄷG1". A autora dessa afirmação, com um lugar social diferenciado no grupo da pré-escola, na medida em que lê e escreve o que lhe confere status de "mais 
avançada da turma", maltrata repetidamente e por diferentes formas a colega " $\mathrm{D}$ ", o faz de forma a não ser percebida pela educadora e sua assistente. No contexto do $3^{\circ}$ ano, "P2 9 9G2", com alto desempenho escolar e representante da turma em diversos eventos, lidera os pares, em especial o grupo de meninas, de forma discreta e contínua, na exclusão e mal tratos à dupla de colegas de etnia cigana: "Só há duas ciganas simpáticas, que é a "D" e a "M", o resto é tudo..." "P2 9 9G2".

Se, no início crianças de etnia cigana e pares de outras turmas são apontados como responsáveis pelas dificuldades no convívio escolar, no decorrer dos grupos focais janelas para um olhar interior são abertas e permitem que os participantes falem sobre os seus papeis sociais no clima social produzido. Emergem vozes e entendimentos resguardados, até então. No caso do $3^{\circ}$ ano, reconhecem fraturas sociais internas numa turma considerada, na comunidade escolar, como profundamente unida. Transitam de uma versão em que afirmam trabalhar em sala de aula ou brincar no pátio com todos os colegas, ao relato de preferências pessoais e de intencionalidades concretizadas em atos para afastar, isolar e excluir das relações alguns colegas.

Não só os pares do grupo étnico cigano são alvos de exclusão social e de diferentes formas de agressão nas três turmas. Em posição semelhante, encontram-se colegas com deficiências, baixo desempenho escolar, de nacionalidade africana, romena e brasileira, ainda há um caso emblemático no $3^{\circ}$ ano de um menino acima do peso e cuja fragilidade na estima própria o leva a querer agradar de todas as formas os agressores.

Nas diversas situações de bullying, os agressores habituais são seletivos nas práticas violentas ou manipulativas. É o caso de $\mathrm{P} 2 \widehat{\jmath} 7 \mathrm{G} 1$, do $1^{\circ}$ ano, contumaz agressor de crianças que não possam opor-lhe resistência ou que não informem $o$ ocorrido de imediato, às auxiliares responsáveis pelos recreios. Perante a professora apresenta-se numa versão bom menino e aluno dedicado. Associado a "J 7 7", também do $1^{\circ}$ ano, e a pares de mais idade, dedica o recreio a maltratar colegas vulneráveis: com deficiências ou avaliados como frágeis. Apesar da proximidade com “J 7 ", também sobre o mesmo exerce poder, estimula a dependência e o desqualifica constantemente.

É grande a possibilidade de que essas microdinâmicas sociais, de dominação e de dependência, entre os pares agressores permaneçam invisíveis aos adultos do contexto. Além de não percebidas são, por vezes, reforçadas pela ação docente. O entendimento da professora de que há valor positivo nas interações da dupla

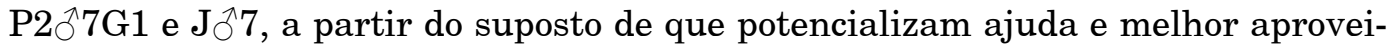


tamento nas atividades de sala de aula, favorece a manutenção de mecanismos de controle, de poder e de submissão entre os mesmos.

Selecionamos aqui dois casos, dentre aqueles constatados nas três turmas, de vitimização não associada à etnia. São representativos dos demais e permitem evidenciar uma coprodução multigeracional nas práticas de bullying no contexto. Essa participação dos adultos é extensiva à totalidade dos quadros de vitimização no campo de pesquisa.

“J○्+7", aluna do $1^{0}$ ano, alvo constante de agressão por diferentes formas é citada nos grupos focais como colega com quem não brincam ou que não deixam

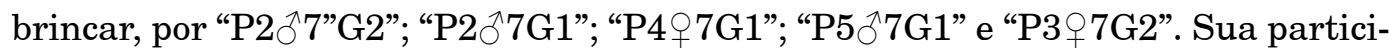
pação nas brincadeiras é condicionada a um personagem fixo depreciativo. "Quando jogamos às bruxas e assim precisamos de uma bruxa, como ninguém quer ser uma bruxa, chamamos a "J". Ela gosta e é mesmo parecida com uma bruxa... E fala como uma bruxa. É tão malvada como uma bruxa.” P2 $37 \mathrm{G} 2$.

Estar em aula não é fator impeditivo às agressões que lhe são dirigidas, sendo os pares agressores cuidadosos para não serem percebidos pela professora nessa intencionalidade. Esses contam com o reconhecimento docente pelo bom desempenho escolar apresentado e pela forma assertiva ao se colocarem como respeitadores das regras de convívio. Ocupam assim um lugar insuspeito que desqualifica possíveis queixas da colega vítima. Dinâmica semelhante se verifica nos casos de bullying nas demais turmas.

As referências dos pares em relação à "J" situam-na num lugar de incapacidade, de não pertencimento, e responsabilizam-na por uma diferença que não compreenderam, porque nisto não contaram com ajuda. Suas particularidades dos parâmetros motores, de linguagem e de pensamento são tomadas como inaceitáveis e o seu desempenho escolar como representação do fracasso absoluto, merecedor de desprezo. "Eu às vezes fico chateado com a "J" na sala de aula. E vocês não sabem o que é que ela faz, um dia estava, ontem estava a comer a cola, no outro dia estava a comer borracha e no outro dia, na segunda-feira estava a comer o lápis assim (exemplifica). E hoje comeu também o lápis." [...]A "J", sabe como é que ela faz? Olhe para aqui para a mesa (exemplifica). E mete uma letra só num caderno todo, uma letra, duma linha abaixo até cima, numa folha de caderno..." P2 $\bigcirc$ 7G2.

Os comentários que, invariavelmente, recebe dos adultos em aula associam-na a uma marca negativa, como a sua falta de atenção, ao que faz errado, a demora na realização das atividades etc. 
Com lugar destinado em mesa na primeira fileira, e próxima à professora, senta-se ao lado de "C", menino de etnia cigana também destinatário de olhares críticos. Compõem a única dupla da sala, considerando-se que as demais crianças estão agrupadas em blocos maiores de mesas. Essa condição diferenciada no espaço é percebida pelos pares: "As mesas são quadradas e a professora só do "C" e da "J" é que puseram uma, e com os outros juntaram junto.” P2 $37 \mathrm{G} 2$. Também é possível que o significado de exclusão subjacente a essa leitura corrobore com o juízo de valor aplicado aos dois colegas. "Eu nunca gostei da "J" nem do "C" porque eles podem trabalhar na mesma mesa, mas vão sempre... mas eles planeiam alguma coisa para nos fazer mal...." P3 $97 \mathrm{G} 2$.

"J" é destinatária permanente de atos bullying, praticados não só por pares da turma como por crianças dos diversos anos, uma situação naturalizada no contexto e a qual não correspondem iniciativas, por parte da equipe docente, com o propósito de promover outros padrões interativos. Recebe pouca ou nenhuma valorização o seu esforço para responder de forma positiva aos desafios da educação escolar e a sua participação diferenciada é motivo contínuo de desqualificação.

Outro caso emblemático no contexto é o de "P4 $8 \mathrm{G} 1$ ", do $3^{\circ}$ ano. Polariza, enquanto alvo, antipatias, críticas, provocações, e agressões físicas. Apresenta queixas frequentes, especialmente dirigidas para uma familiar que integra uma das equipes de trabalho na escola, o que contribui para que seja apontado como um "queixinhas": "[...] o P4, sempre que nós fazemos uma coisinha de nada, ele vai logo dizer à (familiar )e vai "oh (familiar),eles fizeram-me isto", está sempre a fazer queixinhas e nunca diz o que é que ele faz... [...] é queixinhas, nunca diz o que é que ele faz, mas diz o que é que os outros fazem e isso causa algumas confusões e alguns conflitos." P2 9 9G2. "[...] ele vai sempre fazer queixinhas à (familiar), mesmo quando não é nada, ele não conta o que faz, um dia, foi à sua (familiar), ele andava a nos fazer coisas ali no ATL, depois... há um grupo de pessoas que lhe chamaram nomes.... E depois a (familiar) dele foi à nossa sala reclamar conosco.” P3 3 9G2. "[...] o "P4" hoje ia dizer a sua (familiar), mas foi porque eu puxei as calças, mas nem por isso foi contar à... que ele me deu pontapés." $P 1 \precsim 9 G 2$

É notória, na voz das crianças, a dificuldade no convívio com "P4 $\$ 8 \mathrm{G} 1$ ", e são muitos os motivos para a sua discriminação, entendida pelos pares como uma reação aos comportamentos que apresenta. Ao se referir a quem as meninas não confiam, "P2 9 9G2" indica "P4 $8 \mathrm{G} 1$ ", e observa que se trata de uma posição de turma: “[...] na nossa sala é o "P4 3 G1", ninguém gosta de ajudá-lo.” P2 9 9G2. Nesta lógica conta com o reforço de colegas: "[...] anda sempre a resmungar conosco, pensa que 
aqui na escola só ele é que existe porque tem a (familiar) cá e depois arma-se que só ele é que..." P3 3 G2. "Sim, mas ele anda muito, anda muito, como se costuma dizer, saidinho da casca, mas... ele tem que mudar, ele tem que mudar..." P1 ${ }^{\nwarrow}$ 9G2.

Essa problemática nas interações de "P4 $\bigcirc^{\lambda} 8 \mathrm{G} 1$ ” não está circunscrita aos pares do género, ou a um grupo específico de sala de aula. Queixa-se de ser vítima de violência física, de boatos, mentiras e de exclusão por meninos e meninas. Dois episódios nos quais teve a cadeira revestida de cola, pelos colegas, são rememorados pelo grupo e reconhecidos pela vítima como atos de bullying. "Quando me puseram duas vezes cola na cadeira. Estavam a ver se ficava com as calças estragadas...” "P4 8 G1".

Há uma espécie de compromisso dos alunos de melhor desempenho, e da turma como um todo, para manter "P4 $8 \mathrm{G} 1$ " numa condição diferenciada - pela negativa -, para o que se apoiam nas suas especificidades de peso corporal, voz, padrão de movimentos corporais, padrão de respostas aos pares, relação de dependência parental explicitada no convívio com a familiar que trabalha na escola etc.

Constata-se também uma predisposição dos pares para atribuir valores negativos as suas intenções e ações o que, entre outros fatores, contribui para o seu isolamento e potencializa as divergências:

[...] ele quer criar muita confusão que é para depois culpar os outros. Culpar os outros para ficar de castigo, ele quer, o que ele quer é ser o único a ir para o recreio, que é isso que ele quer, mas, por isso, é que ele cria confusão, mas depois nós, o $3^{\circ} \mathrm{A}$, como nós dissemos e criamos uma música também " 3 " A unido nunca mais será vencido", por ninguém mesmo... P1 $9 \mathrm{G} 2$.

Habitualmente o grupo recorre à argumentação para reforçar a ideia de ser “P4 8 G1" o culpado pelos diversos problemas nas interações.

[...] o P4 $8 \mathrm{G} 1$ sempre a tentar bater-nos. Hoje quando estava a fazer xixi, as minhas necessidades, digamos, ele veio a tentar bater-me, eu estava a fazer as minhas necessidades hoje e ele começa a dar-me pontapés, começa a dar-me pontapés, muitos e eu fui chamar uma funcionária $\mathrm{P} 1{ }^{\top} 9 \mathrm{G} 2$.

Em relação a esse fato específico, e apesar da unidade inicial do grupo, manifesta-se uma voz dissonante, num ineditismo de participação facilitada no grupo focal, que confronta a versão apresentada e indica que a violência física de "P4 ${ }^{\wedge} 8 \mathrm{G} 1$ " terá sucedido uma agressão cometida por "P1 $\bigcirc \mathrm{G} 2$ ".

Também hoje aconteceu, que não digas só do "P4 $\delta^{\wedge} 8 \mathrm{G} 1$ ", que estava na casa de banho e 0

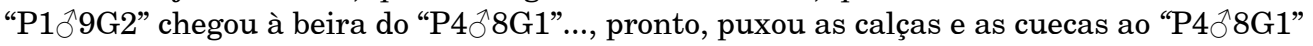
e toda a gente viu, todos os que estavam lá dentro e estavam fora. $\mathrm{P} 3{ }^{\dagger} 9 \mathrm{G} 1$. 
O exercício participativo das crianças nos grupos focais confronta a ideia de entreajuda e inclusão, automatizada como espelho das interações na turma, e torna possível pensar num cotidiano de invisibilidade da violência entre pares. "Desculpe interromper, mas elas também não deixam jogar o "P4 3 G 81 " só porque ele é gordo e isso não pode ser.” P3 $\overbrace{}^{\Uparrow} 9 \mathrm{G} 1$.

O peso corporal de "P4 $8 \mathrm{G} 1$ ", acima da média, determina uma participação levemente diferenciada nos jogos e brincadeiras, nomeadamente nas atividades de maior movimentação corporal. A essa condição física soma-se uma rotina sedentária e a superproteção de uma familiar que também compõe o quadro de profissionais da escola. Contudo, apresenta um conjunto ampliado de habilidades corporais e não lhe faltam condições físicas para participar de quaisquer atividades no âmbito dos jogos e brincadeiras. Mesmo assim permanece solitário nos recreios, que decorrem em tentativas vãs de aproximação, por vezes vividos num espaço separado, que está sob a responsabilidade da sua familiar.

Percebe-se, num contexto que demanda condutas defensivas, o quão difícil torna-se para "P4 $₫ 8 \mathrm{G} 1$ " uma atitude espontânea e não focada no impacto das suas iniciativas. No grupo focal, quando emerge a lembrança dos episódios em que teve a cadeira cheia de cola, ensaia uma posição nova, que não a de vítima habitual dos pares, e comenta que os agressores não conseguiram provocar o dano pretendido. Assinala, que caso o fizessem teriam que pagar-lhe calças novas. Dessa forma, alerta para uma consequência da ação, e minimiza o alcance da agressão perpetrada contra si: "[...] não ficaram estragadas. Era daquela de stick."

Uma lógica binária de organização da sala de aula, esvaziada da participação das crianças e concretizada na definição unilateral do lugar onde cada uma deve sentar é dada a conhecer nos grupos focais do $3^{\circ}$ ano. Condiciona interações e papéis sociais. "As mesas estão organizadas por grupos, os grupos que trabalham melhor e os grupos que são mais atrasados." "P4 ${ }^{\top} 8 \mathrm{G} 1$ ". A categorização em dois grupos é também mencionada por "P2 9 9G2", que identifica 10 crianças pertencentes ao grupo das crianças com "mais dificuldade em aprender". Situa "P4 $\$$ G1" nesse conjunto.

Essa lógica de organizar a sala, as leituras das crianças sobre o pertencimento a um dos grupos, a demarcação entre "nós e eles" que se estabelece pela ideia de melhor e de pior, bem como as referências de convívio que dissemina, são forças da socialização institucionalizada e precisam ser interpretadas nas suas relações com o bullying.

Nas três turmas, foi observada a ação influente das crianças, na recusa a um pacto de desqualificação, quando os alvos eram participantes ativos de jogos e brincadeiras. $\mathrm{O}$ caso de "P $\mathrm{P} 5$ ", da pré-escola, revela como o fato de ter amigos e 
partilhar com eles uma interatividade lúdica é vital ao pertencimento - neutraliza fragilidades e evita possível vitimização. Constitui um bom exemplo de inclusão na cultura de pares apesar das dificuldades apontadas pela educadora. Conforme excerto do diário de campo: [...] suas limitações motoras não representam impedimentos, não hesita em apresentar-se para integrar a equipe de futebol e demais atividades dos tempos livres, mostra-se confiante, diversifica interações e faz-se ativo. Não há quaisquer indicativos de que seja vítima de bullying nas interações com os pares. Essa participação plena nas situações informais é também reconhecida pela educadora. "[...] até o meu "P $\mathrm{P} 5$ ", com as limitações que ele tem, interage muito bem, é verdade. Então a brincar eles adoram-no, é, porque ele é muito bom a brincar, apesar das dificuldades que tem..." (Educadora $\mathrm{M}$ ).

Também não se aplicam as lógicas de exclusão social, comuns nessa cultura escolar, às crianças do $1^{\circ}$ e do $3^{\circ}$ ano reconhecidas antes como participantes esperadas e valorizadas nas interações lúdicas, do que pelo seu não êxito, mesmo que esse seja continuamente assinalado pelos adultos do contexto.

Entre as crianças diretamente envolvidas em atos de bullying observa-se uma característica comum, que varia da dificuldade à incapacidade para participar nos processos de jogo e de brincadeira, notadamente naquilo que diz respeito à capacidade de envolvimento, enlevamento, convergência de intenções, de ações e de comunicação com os pares. Esse arranjo de condições - a impossibilidade intrínseca para o protagonismo lúdico associada a iniciativas de bullying dirigido aos pares -, é sugestivo de frágil capacidade empática. Nesse sentido conflitos de interesse contaminam a cena lúdica e a condicionam.

Assim, em cada criança que pratica o bullying há um brincante incapacitado para a brincadeira, que também é penalizado por não usufruir de um agir social pacífico comum ao grupo. As vítimas, entretanto, produzem esforços incansáveis com vistas à participação, à inclusão, aos laços e à pertença aos grupos de pares, no que não obtém êxito. Nenhum desses protagonistas - agressores e vítimas - vivencia a condição de brincante em plenitude.

\section{Discussão}

Da presença diária das crianças na escola, durante cinco dias da semana, repetida ao longo de meses e anos não se faz uma plataforma de geração e organização de conhecimento com e sobre essas. Mantém-se o princípio da negatividade (Sarmento, 2011), que não reconhece capacidades nas crianças, determinando-lhes 
interdições e prescrições. Preconceitos, estereótipos, solidão e mal-estar são facilmente disseminados na cultura escolar, e não se observa que desacomodem o olhar docente. Indicativos da necessidade de um agir institucional que não exclua das suas diretrizes os saberes das crianças, e a realidade produzida no contexto são um apelo ao compromisso com um modelo socializador que não é o do presente.

Precisam ser conhecidas as implicações de uma geração que, sem hipótese de contar com a mediação de adultos efetivamente dispostos a esse papel, silencia sistematicamente pensamentos, emoções e decisões; converte as suas dúvidas, pressupostos e estereótipos sociais em ações não mediadas pelo diálogo multigeracional e, que aos poucos, se especializa na arte de fazer crer ao adulto a observância de normativas por ele determinadas, ao tempo em que não as confirma no convívio nessa comunidade.

Se não há genuíno interesse na observação da cultura produzida pelas crianças na escola, essas mostram uma atitude curiosa e interpretativa diante dos padrões do agir adulto, a partir do que apresentam respostas adaptadas, como por exemplo, nos "interrogatórios" que se seguem a sua participação em conflitos. Para minimizar ou evitar punições recorrem a estratagemas defensivos, tais como antecipar-se e afirmar que "foi sem querer", exitosos às finalidades, diante do tão previsível quanto superficial roteiro de questionamentos, que em nada fomenta uma formação ética e com essa a qualificação das interações. Há ainda os abraços impostos, acompanhados de contagem em sequência numérica, pelos demais pares. É inegável que provocam efeitos positivos imediatos no humor das crianças, entretanto é ação de tamponamento que ignora as suas capacidades reflexivas e propositivas.

Igualmente preocupante na forma escolar, é a sua propriedade de anular a expressão do senso moral das crianças. Verificam-se nas três turmas, mecanismos pouco favoráveis a uma participação social orientada pela verdade, se entendida como uma percepção crítica não manipulada/manipuladora das vivências do cotidiano. Esses sujeitos sociais crianças, tão dispostos quanto capazes de uma intencionalidade ética, que os desobriga de versões ou alianças de conveniência, ou se necessário os sustenta pacificamente em posições contrárias as dos amigos, são balizadores que qualificam as interações e restabelecem algum equilíbrio a relações tão assimétricas. Poderiam ser potencializados na sua ação influente, se assim reconhecidos, para o que uma cultura dialógica seria necessária. Não há, nos achados de investigação, qualquer registro que indique ciência ou valorização desse papel social agregador, democrático e restaurativo, com o que perde força 0 projeto de educação cidadã professado pela escola. 
Na medida em que a violência física é uma constante na escola, nota-se a insuficiência dos meios adotados para evitá-la. Há clareza nas narrativas das crianças quanto à ação dos amigos serem um importante fator protetivo e resolutivo, todavia aguardam por reconhecimento adulto a ação influente que as crianças exercem entre si, bem como os sentimentos de pertença e reciprocidade como valores centrais da cultura de pares. Não faltam, portanto, indicativos à geração dominante, para a necessidade de abandonar o paradigma de legislar para e sobre a infância, extraindo-lhe a diversidade e a complexidade.

Escutar as crianças; buscar interações sensíveis às suas múltiplas possibilidades de comunicar; valorizar a iniciativa autônoma como promotora do próprio conhecimento; afirmar uma metodologia em que a rotina seja sinônimo de regularidade nos fatos, nos espaços e no tempo como base do conhecimento de si e do contexto (FALK, 2004) é uma decisão política, administrativa e pedagógica para organizar um processo educativo de recusa à dominação e a transformação acelerada desses sujeitos sociais em escolares. Antes, trata-se de garantir uma estrutura plena de oportunidades para que acionem suas capacidades de pensamento e de linguagem.

A garantia, nos grupos focais, desse espaço ao pensamento autoral, livre para produzir lógicas inéditas, permite conhecer as crianças concretas e as suas leituras ostracizadas no/do contexto. É nesse agir reflexivo que se reconhecem num protagonismo transgressor primeiramente atribuído aos pares do grupo étnico cigano, e que se desapegam de versões convenientes, também convergentes com a lógica adulta, de que a sala de aula em termos de convívio é um oásis de calmaria.

Os grupos focais mostram-se boas ferramentas para confrontar o discurso costumeiro, e a polarização enraizada. São convites às crianças para a ousadia de olhar, ver e pronunciar-se sem recorrer às máscaras sociais usadas no cotidiano, ou ainda a partir de outras referências e papéis sociais. É neste sentido que inaugurando um diálogo autoral, uma ética própria, que não vincula a qualquer ventriloquismo, os pares interrogam o discurso de $\mathrm{P} 1 \delta 9 \mathrm{G} 2$, não se deixam impressionar pelo seu fluente aparato argumentativo, confrontando-o na sua corresponsabilidade e iniciativas recorrentes de agressão à $\mathrm{P} 4 \bigcirc \mathrm{G} 1$. Em situação inédita às vivências do grupo, o estatuto social vigente na turma é alterado e, o fator desempenho escolar é relativizado no seu poder de determinar o polo da razão/verdade e o da sua antítese. Isto é possível porque vozes ganham liberdade, são descomprimidas da violência das margens apertadas, que determinam a direção e o nível da vazão, por conseguinte, o que fica retido. Cada grupo focal permite-se deixar de seguir à 
risca os discursos prontos e batidos que enchem de palavras mortas o mundo da escola e o seu cotidiano.

Por instantes, a partir da intencionalidade reflexiva feita pelo grupo de pares, P4 ${ }^{\top} 8 \mathrm{G} 1$, é reconhecido num outro lugar que não o da negatividade. Esse novo lugar, até então situado em área utópica fortalece-o para apresentar uma voz desconhecida, porque costumeiramente recebida com resistências. O diálogo, que não acirra animosidades, inaugura uma revisão histórica e não se furta à análise crítica, na primeira pessoa, dos papéis sociais exercidos.

Essa disposição retrospectiva, a tocar o campo propositivo, descarta justificativas estáveis e faz emergir conteúdos até então silenciados, determinantes à qualidade das interações entre pares. É assim, em narrativas corajosas, que preconceitos e interesses são reconhecidos: não deixar jogar porque é gordo, aproximar-se para obter o empréstimo da bola, estar junto no recreio para jogar no computador garantido pela familiar do colega... Também o é, numa condição de escuta incomum pelos pares, a queixa de $\mathrm{P} 4 \hat{\wedge} 8 \mathrm{G} 1$ à brutalidade dos colegas e os sentimentos decorrentes.

\section{Considerações Finais}

Em acordo à literatura sobre o bullying na infância, confirma-se o recurso às formas verbal e física como as mais frequentes nas três turmas, entretanto, práticas que visam a exclusão das vítimas dos grupos de pares, consideradas as mais comuns entre adolescentes, também são recorrentes, com destaque no grupo do $3^{0}$ ano.

Escolas que impõem uma norma de silenciamento diante do bullying concorrem para uma condição de duplo sofrimento das vítimas, na medida em que lhes reduzem o poder de resposta frente ao assédio.

Em síntese, mesmo que ações agressivas não sejam toleradas pelo conjunto de profissionais da escola, se identificadas, há que se observar, como regra, a não valorização das crianças vitimizadas pelos pares quer por parte das professoras quer da educadora quer das funcionárias.

É inadiável a decisão e a ousadia para reinventar-se como uma escola para todos, portanto, como modelo que não teme o pensamento, a voz e a ação das crianças, manifestadas em múltiplas linguagens, e em acordo a sua diversidade. Processos socializadores que se estendem por até onze horas diárias, ao longo dos três anos de educação de infância e dos quatro anos do $1^{\circ} \mathrm{CEB}$ são fundantes de subjetividades. Podem concorrer para transformar a criança/sujeito em criança/objeto. Há que se ter a certeza de haver consciência do que se produz, e o suficiente domínio dessa 
organização para modificá-la na medida dos indicadores vivos da socialização em curso. Esse é também o caminho incontornável para desmistificar entendimentos de bullying e olhar a problemática, tal qual ela se manifesta, por meio das linguagens das crianças.

\section{Referências}

BOULTON, M., \& SMITH, P. Bully/victim problems in middle-school children: Stability, selfperceived competence, peer perceptions and peer acceptance. British Journal of Developmental Psychology, 12, p. 315-329. New York, 1994.

BRONFENBRENNER, U. A Ecologia do Desenvolvimento Humano: experimentos Naturais e Planejados. Porto Alegre, Artes Médicas, 1996.

CARVALHOSA, S., LIMA, L., \& MATOS, M. Bullying: A provocação/vitimação entre pares no contexto escolar português. Análise Psicológica, v. 4, XIX, p. 523-537, 2001.

COSTA, Paulo J.F.S.; FARENZENA, R. SIMÕES, H.; PEREIRA, B. O. Adolescentes portugueses e o bullying escolar: estereótipos e diferenças de género. Interacções n. 25, p. 180-201, 2013a. Disponível em:< http://hdl.handle.net/1822/25647> Acesso em: 23 ago. 2015.

COSTA, P. J.F.S.; FARENZENA, R.; SIMÕES, H.; PEREIRA, B. O. Violência, bullying e indisciplina na escola: bullying escolar: um estudo longitudinal sobre vitimação. Atas do IX Seminário Internacional de Educação Física, Lazer e Saúde. 2013b. Disponível em: http://hdl.handle. net/1822/26341. Acesso em: 15 set. 2015.

COSTA, P., PEREIRA, B., SIMÕES, H., \& FARENZENA, R. Vitimação em Contexto Escolar: frequência e multiplas formas. Paper presented at the VII Seminário Internacional de Educação Física, Lazer e Saúde, Instituto de Educação da Universidade do Minho - Campus de Gualtar. Braga, 2011.

CRAIG, W. M. The relationship among bullying, victimization, depression, anxiety, and aggression in elementary school children. Personality and Individual Differences, Volume 24, Issue 1, January 1998, p. 123-130.

DEHAAN, L. Bullies. 1997. Revisado em 2009. Disponível em: http://www. ag.ndsu.edu/pubs/yf/ famsci/fs570.pdf. Acesso em: 18 ago. 2013.

ESPELAGE, L.D. Ecological Theory: Preventing Youth Bullying, Aggression, and Victimization. Theory Into Practice. v.53, Issue 4. Special Issue: Theories of Bullying and Cyberbullying P. 257-264. Routledge - Taylors \& Francis Group, 2014.

ESTÉVEZ, E.; MURGUI, S.; MUSITU, G.; MORENO, D. Adolescent aggression: effects of gender and family and school environments. Journal of Adolescence, 31, p. 433-450, 2008.

FALK, J. (Org.). Educar os três primeiros anos: a experiência de Lóczy. Tradução de Suely Amaral Mello - revisão de Jaqueline Moll. Araraquara: JM Editora, 2004.

FANTE, C. Fenômeno Bullying: como prevenir a violência nas escolas e educar para a paz. 2. ed. rev. Campinas, SP: Verus editora, 2005. 
FERNANDES, L. e SEIXAS, S. Plano Bullying: como apagar o bullying da escola. Lisboa: Plátano Editora, 2012.

FERRER, Belén M.; RUIZ, David M.; AMADOR, Luis V. and ORFORD, Jim. School Victimization Among Adolescents. An Analysis from an Ecological Perspective. Psychosocial Intervention. v. 20, n. 2, 2011.p. 149-160.

GARCIA, Mauricio \& MADRIAZA, Paulo. Estudio cualitativo de los determinantes de la violencia escolar en Chile, Estudos de Psicologia 2006, 11(3), 247-256, Chile.

GUERRA, Nancy G.; WILLIAMS, Kirk R. and SADEK, Shelly. Understanding Bullying and Victimization During Childhood and Adolescence: A Mixed Methods Study. Child Development. January/February 2011, Volume 82, Number 1, Pages 295-310.

KOCHENDERFER-Ladd, B., \& WARDROP, J. Chronicity and instability of children's peer victimization experiences as predictors of loneliness and social satisfaction trajectories. Child Development, 72(1), 134-151. New York, 2001.

LEE, Chang-Hun. An Ecological Systems Approach to Bullying Behaviors Among Middle School Students in the United States. Journal of Interpersonal Violence. May 2011 26: 16641693, Sage Journals.

MARQUES, A.R. Jogo de luta ou luta a sério? Como distinguir para decidir? Cadernos de Educação de Infância n. 90 Ago/10 24-30. Lisboa: Associação Portuguesa de Educadores de Infância, 2010.

MARQUES, Amália; NETO, C.; ÂNGULO, J.C.; e PEREIRA, Beatriz O. Um olhar sobre o recreio, espaço de jogo, aprendizagem e alegria mas também de conflito e medo.In: ESTRELA, Albano e FERREIRA, Júlia. Indisciplina ET Violence à L'Ecole, Lisboa, Editora Afirse, p. 553560, 2002.

MARTINS, M. (Ed.). Maus - tratos entre adolescentes na escola. Penafiel: Editorial Novembro, 2009.

MARTINS, M. J. D. Violência interpessoal e maus-tratos entre pares. Em contexto escolar. Revista de Educação, Vol. XV, n. 2, 200751 - 78. Revista do Departamento de Educação da Faculdade de Ciências da Universidade de Lisboa.

MATOS, M., NEGREIROS, J., SIMÕES, C., \& GASPAR, T. Definição do problema e caracterização do fenómeno. In H. C. F. C. Ferreira-Borges (Ed.), Violência, Bullying e Delinquência. Lisboa: Coisas de Ler Edições, 2009.

MEYER, E. (Ed.). Gender and sexual diversity in school:explorations of educational purpose (Vol. 10). London-New York: Springer Dordrecht Heidelberg, 2011.

NEGREIROS, J. Relação entre comportamentos agressivos e outros comportamentos desviantes nos jovens: um estudo em meio escolar. In CORREIA, J. \& MATOS, M. (Eds.). Violência e violências da e na escola. p..73-81. Porto: Edições Afrontamento, 2003.

OLWEUS, D. The Olweus Bullying Prevention program: Design and implementation issues and a new national initiative in Norway. In Smith, P. K., PEPLER, D. \& RIGBY, K. (Eds.), Bullying in schools, how successful can interventions be? Cambridge: Cambridge University Press, 2004.

OLWEUS, D. Annotation: bullying at school: basic facts and effects of a school based intervention program. Journal of Psychology and Psychiatry, n.43, v.7, p. 1171-1190, 1994. 
OLWEUS, D. Bullying at school. Oxford e Cambridge: Blackwell, 1993.

OLWEUS, D. (1991). Bully/victim problems among schoolchildren: Basic facts and effects of a school based intervention program. In PEPLER, D. and RUBIN, K. (Eds.), The development and treatment of childhood aggression.(411-448) Hillsdale, NJ: Erlbaum, 1991.

OLWEUS, D. Prevalence and incidence in study of anti-social behavior: definitions and measurement. In: M. E. KLEIN (Ed.), Cross - national research in self-reported crime and delinqency (p. 187-201). Dordrecht, The Netherlands: Kluwer, 1989.

PEREIRA, B. (Ed.). Para uma escola sem violência. Estudo e prevenção das práticas agressivas entre crianças ( $2^{\underline{a}}$ ed.). Lisboa: Fundação Calouste Gulbenkian e Ministério da Ciência e Tecnologia 2008.

ROOS, S., SALMIVALLI, C., \& HODGES, E. Person X context effects on anticipated moral emotions following aggression. Social Development, 2011.

SALMIVALLI, C. Bullying and the peer group: A review; Aggression and Violent Behavior n.15, 2010, p. 112-120.

SALMIVALLI, C. \& NIEMINEN, E. Proactive and reative agression among school bullies, victimims, and bully/victimims. Agressive Behavior, 28, p. 30-44, 2002.

SANMARTIN, J. Concepto y tipos. In Á. Serrano (Ed.), Acoso y violencia en la escuela p. 21-32. Barcelona: Editorial Ariel. S.A, 2006.

SARMENTO, M. J. Estudos da infância e sociedade contemporânea: desafios conceptuais, Revista O Social em Questão. Revista da PUC-Rio de Janeiro, XX, n. 21 p. 15-30, 2009.

SKRZYPIEC, G., SLEE, P., MURRAY-HARVEY, R., \& PEREIRA, B. School bullying by one or more ways: Does it matter and how do students cope? School Psychology International, v. 32, n. 3, p. 288-311, 2011. doi: 10.1177/0143034311402308

SMITH, P. K. School Bullying. Sociologia, problemas e práticas, n. 71, p. 81-98. DOI:10.7458/ SPP2012702332, 2013.

SMITH, P. K. \& SHARP, S. School Bullying. Insigts and perspectives, Londres e Nova Yorque, Routledge, 1994.

SOUZA, R.; PEREIRA, B. e LOURENÇO, L. M. O bullying, locais e representações dos recreios. Estudo com crianças de uma escola básica de $5^{\circ}$ e $6^{\circ}$ anos. In.: BARBOSA, G.; LOURENÇO, L. M. e PEREIRA, B. (org.). Bullying: conhecer e intervir. Juíz de Fora: ed UFJF, 2011, p. $33-50$.

SPRIGGS, Aubrey L.; IANNOTTI, Ronald J.; NANSEL, Tonja R.; HAYNIE, Denise L. Adolescent bullying involvement and perceived family, peer and school relations: commonalities and differences across race/ethnicity. Journal of Adolescent Health. Volume 41, Issue 3, September 2007, p. 283-293. 